\title{
Lean-Based Redesign of Multidisciplinary Rounds on General Medicine Service
}

\author{
Marlena Kane, MPH, MSW', Nidhi Rohatgi, MD, MS²*, Paul A. Heidenreich, MD², Akanksha Thakur, MD², Marcy Winget, PhD², \\ Kenny Shum, PhD1', James Hereford, MS³, Lisa Shieh, MD, PhD², Thomas Lew, MD², Jason Hom, MD², Jeffrey Chi, MD², \\ Ann Weinacker, MD², Timothy Seay-Morrison, MSW', Neera Ahuja, MD²
}

${ }^{1}$ Stanford Health Care, Stanford, California; ${ }^{2}$ Stanford University School of Medicine, Stanford, California; ${ }^{3}$ Fairview Health Services, Minneapolis, Minnesota.

BACKGROUND: Multidisciplinary rounds (MDR) facilitate timely communication amongst the care team and with patients. We used Lean techniques to redesign MDR on the teaching general medicine service.

OBJECTIVE: To examine if our Lean-based new model of MDR was associated with change in the primary outcome of length of stay (LOS) and secondary outcomes of discharges before noon, documentation of estimated discharge date (EDD), and patient satisfaction.

DESIGN, SETTING, AND PATIENTS: This is a pre-post study. The preperiod (in which the old model of MDR was followed) comprised 4000 patients discharged between September 1, 2013, and October 22, 2014. The postperiod (in which the new model of MDR was followed) comprised 2085 patients between October 23, 2014, and April 30, 2015.

INTERVENTION: Lean-based redesign of MDR.

MEASUREMENTS: LOS, discharges before noon, EDD, and patient satisfaction.

RESULTS: There was no change in the mean LOS. Discharges before noon increased from $6.9 \%$ to $10.7 \%$ ( $P$ $<.001$ ). Recording of EDD increased from $31.4 \%$ to $41.3 \%$ $(P<.001)$. There was no change in patient satisfaction.

CONCLUSIONS: Lean-based redesign of MDR was associated with an increase in discharges before noon and in recording of EDD. Journal of Hospital Medicine 2018;13:482-485. Published online first February 2, 2018. (C) 2018 Society of Hospital Medicine

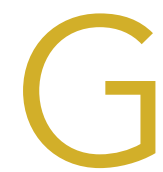
iven that multiple disciplines are often involved in caring for patients admitted to the hospital, timely communication, collaboration, and coordination amongst various disciplines is necessary for safe and effective patient care. ${ }^{1}$ With the focus on improving patient satisfaction and throughput in hospitals, it is also important to make more accurate predictions of the discharge date and allow time for patients and their families to prepare for discharge..$^{2-4}$

Multidisciplinary rounds (MDR) are defined as structured daily communication amongst key members of the patient's care team (eg, nurses, physicians, case managers, social workers, pharmacists, and rehabilitation services). MDR have shown to be a useful strategy for ensuring that all members of the care team are updated on the plan of care for the patient. ${ }^{5}$ During MDR, a brief "check-in" discussing the patient's plan of care, pending needs, and barriers to discharge allows all team members, patients, and families to effectively coordinate care and plan and prepare for discharge.

\footnotetext{
*Address for correspondence: Nidhi Rohatgi, MD, MS, 1265 Welch Road, Mail code 5475, Stanford, CA 94305; Telephone: 650-498-4094; Fax: 650-723-8596; E-mail: nrohatgi@stanford.edu

Additional Supporting Information may be found in the online version of this article.

Received: February 23, 2017; Revised: September 11, 2017; Accepted: October 15, 2017
}

(C) 2018 Society of Hospital Medicine DOI 10.12788/jhm.2908
Multiple studies have reported increased collaboration and improved communication between disciplines with the use of such multidisciplinary rounding. ${ }^{2,5-7}$ Additionally, MDR have been shown to improve patient outcomes ${ }^{8}$ and reduce adverse events, ${ }^{9}$ length of stay (LOS), ${ }^{6,8}$ cost of care ${ }^{8}$ and readmissions. ${ }^{1}$

We redesigned MDR on the general medicine wards at our institution in October 2014 by using Lean management techniques. Lean is defined as a set of philosophies and methods that aim to create transformation in thinking, behavior, and culture in each process, with the goal of maximizing the value for the patients and providers, adding efficiency, and reducing waste and waits. ${ }^{10}$

In this study, we evaluate whether this new model of MDR was associated with a decrease in the LOS. We also evaluate whether this new model of MDR was associated with an increase in discharges before noon, documentation of estimated discharge date (EDD) in our electronic health record (EHR), and patient satisfaction.

\section{METHODS}

Setting, Design, and Patients

The study was conducted on the teaching general medicine service at our institution, an urban, 484-bed academic hospital. The general medicine service has patients on 4 inpatient units (total of 95 beds) and is managed by 5 teaching service teams.

We performed a pre-post study. The preperiod (in which the old model of MDR was followed) included 4000 patients discharged between September 1, 2013, and October 22, 2014. The postperiod (in which the new model of MDR was followed) 
TABLE 1. Interventions Performed in the Old and New Model of MDR

\begin{tabular}{|c|c|}
\hline Old Model of MDR & New Model of MDR \\
\hline Rounds were conducted away from the inpatient unit in a conference room. & Rounds were conducted at the nurse's station on each inpatient unit. \\
\hline Rounds started at 11 am and were conducted Monday to Friday, excluding holidays. & Rounds started at 10 am and were conducted Monday to Friday, excluding holidays. \\
\hline Rounds usually lasted about 10 minutes. & Rounds lasted up to 30 minutes per team. \\
\hline $\begin{array}{l}\text { Rounds did not incorporate a visibility board (a tool used to provide at-a-glance visual display of } \\
\text { work of the organization and allow for quick recognition of information being communicated and } \\
\text { abnormal conditions in order to maximize efficiency and clarity and promote collaboration and } \\
\text { team work). }\end{array}$ & $\begin{array}{l}\text { Rounds were done in front of a large visibility board. This board was updated in real time during } \\
\text { rounds by the case manager and included the estimated date and time of discharge. }\end{array}$ \\
\hline $\begin{array}{l}\text { Rounds were attended by a general medicine housestaff from each of the } 5 \text { teams and a case } \\
\text { manager and had inconsistent representation from some of the clinical support services (such as } \\
\text { clinical nutrition or rehabilitation services). Rounds did not include the bedside nurse or the general } \\
\text { medicine attending physician. }\end{array}$ & $\begin{array}{l}\text { Rounds were attended by each team's general medicine case manager, social worker, pharmacist, } \\
\text { attending physician, respiratory therapist, rehabilitation services, clinical nutritionist, charge nurse, } \\
\text { and bedside nurse. }\end{array}$ \\
\hline $\begin{array}{l}\text { There was no consistent format to identify the pending needs of the patients and potential barriers } \\
\text { to discharge or provide relevant communication to the patients and/or their families after rounds. } \\
\text { Either the inpatient unit charge nurse or the bedside nurse updated the EDD on the EHR. }\end{array}$ & $\begin{array}{l}\text { Standard work was developed to create a consistent format to identify pending needs of the patients } \\
\text { and potential barriers to discharge. The bedside nurse provided relevant communication to the } \\
\text { patients and/or their families after these rounds and also updated the EDD in our EHR. }\end{array}$ \\
\hline The general medicine housestaff usually facilitated the discussion at rounds. & The case manager facilitated the discussion at rounds. \\
\hline
\end{tabular}

NOTE: Abbreviations: EDD, estimated discharge date; EHR, electronic health record; MDR, multidisciplinary rounds.

included 2085 patients discharged between October 23, 2014, and April 30, 2015. We excluded 139 patients that died in the hospital prior to discharge and patients on the nonteaching and/or private practice service.

All data were provided by our institution's Digital Solutions Department. Our institutional review board issued a letter of determination exempting this study from further review because it was deemed to be a quality improvement initiative.

\section{Use of Lean Management to Redesign our MDR}

Our institution has incorporated the Lean management system to continually add value to services through the elimination of waste, thus simultaneously optimizing the quality of patient care, cost, and patient satisfaction. ${ }^{11}$ Lean, derived from the Toyota Production System, has long been used in manufacturing and in recent decades has spread to healthcare. ${ }^{12} \mathrm{We}$ leveraged the following 3 key Lean techniques to redesign our MDR: (1) value stream management (VSM), (2) rapid process improvement workshops (RPIW), and (3) active daily management (ADM), as detailed in supplementary Appendix 1.

\section{Interventions}

Our interventions comparing the old model of the MDR to the new model are shown in Table 1. The purpose of these interventions was to (1) increase provider engagement and input in discharge planning, (2) improve early identification of patient discharge needs, (3) have clearly defined roles and responsibilities for each team member, and (4) have a visual feedback regarding patient care plan for all members of the care team, even if they were not present at MDR.

\section{Outcomes}

The primary outcome was mean LOS. The secondary outcomes were (1) discharges before noon, (2) recording of the
TABLE 2. Patient Characteristics

\begin{tabular}{lccc}
\hline Characteristic & $\begin{array}{c}\text { Preperiod } \\
\mathbf{( N = 4 0 0 0 )}\end{array}$ & $\begin{array}{c}\text { Postperiod } \\
\mathbf{( N = 2 0 8 5 )}\end{array}$ & $\begin{array}{c}\text { P value } \\
\text { for Differences }\end{array}$ \\
\hline Age, years (mean \pm SD) & $59.6 \pm 19.7$ & $60.0 \pm 19.8$ & .365 \\
\hline Females (n, \%) & $2043(51.1 \%)$ & $1039(49.9 \%)$ & .367 \\
\hline Race/ethnicity (n, \%) & & & .769 \\
Asian & $493(12.3 \%)$ & $239(11.5 \%)$ & \\
African American & $398(10.0 \%)$ & $222(10.6 \%)$ & \\
Hispanic & $785(19.6 \%)$ & $409(19.6 \%)$ & \\
Non-Hispanic white & $1839(46.0 \%)$ & $968(46.4 \%)$ & \\
Pacific Islander & $138(3.4 \%)$ & $62(3.0 \%)$ & .137 \\
Other/Unknown & $347(8.7 \%)$ & $185(8.9 \%)$ & \\
\hline Spoken language (n, \%) & & & \\
English & & 1.071 \\
Spanish & $3224(80.6 \%)$ & $1693(81.2 \%)$ & \\
Other & $436(10.9 \%)$ & $197(9.4 \%)$ & \\
\hline CMI (mean \pm SD) & $340(8.5 \%)$ & $195(9.4 \%)$ & \\
\hline Discharge volume (average per day) & $1.35 \pm 1.11$ & $1.40 \pm 1.06$ & \\
\hline
\end{tabular}

NOTE: Abbreviations: CMI, case mix index; SD, standard deviation.

EDD in our EHR within 24 hours of admission (as time stamped on our EHR), and (3) patient satisfaction.

Data for patient satisfaction were obtained using the Press Ganey survey. We used data on patient satisfaction scores for the following 2 relevant questions on this survey: (1) extent to which the patient felt ready to be discharged and (2) how well staff worked together to care for the patient. Proportions 
TABLE 3. Primary and Secondary Outcomes

\begin{tabular}{|c|c|c|c|c|}
\hline Outcomes & Preperiod $(\mathrm{N}=4000)$ & Postperiod $(\mathrm{N}=2085)$ & Absolute Difference (95\% Cl) & $P$ value for Differences \\
\hline Mean LOS (days) & 4.66 & 4.81 & $0.15(-0.10$ to 0.40$)$ & .227 \\
\hline Mean length of stay (CMI adjusted days) & - & - & $0.05(-0.17$ to 0.26$)$ & .665 \\
\hline Discharges before noon $(n, \%)$ & $275(6.9 \%)$ & $224(10.7 \%)$ & $3.9 \%$ (2.4 to 5.3$)$ & $<.001$ \\
\hline $\begin{array}{l}\text { Estimated discharge date recorded on our EHR } \\
\text { within } 24 \text { hours of admission }(n, \%)\end{array}$ & $1256(31.4 \%)$ & $861(41.3 \%)$ & $9.9 \%$ (7.4 to 12.4$)$ & $<.001$ \\
\hline \multicolumn{5}{|l|}{ Patient satisfaction } \\
\hline $\begin{array}{l}\text { (1) Extent to which patient felt ready to be } \\
\text { discharged }(n, \%)\end{array}$ & $275(61.1 \%)$ & $106(58.9 \%)$ & $-2.2 \%(-10.7$ to 6.2$)$ & .607 \\
\hline $\begin{array}{l}\text { (2) How well staff worked together to care for } \\
\text { patient }(n, \%)\end{array}$ & $342(74.5 \%)$ & $137(74.5 \%)$ & $0.0 \%(-7.5$ to 7.4$)$ & .989 \\
\hline
\end{tabular}

NOTE: Abbreviations: $\mathrm{Cl}$, confidence interval; CMI, case mix index; EHR, electronic health record; LOS, length of stay.

of the "top-box" ("very good") were used for the analysis. These survey data were available on 467 patients (11.7\%) in the preperiod and 188 patients (9.0\%) in the postperiod.

\section{Data Analysis}

Absolute difference in days (mean LOS) or change in percentage and their corresponding 95\% confidence intervals (Cls) were calculated for all outcome measures in the pre-post periods. Two-tailed t tests were used to calculate $P$ values for continuous variables. LOS was truncated at 30 days to minimize the influence of outliers. A multiple regression model was also run to assess change in mean LOS, adjusted for the patient's case mix index (CMI), a measure of patient acuity (Table 3). $\mathrm{CMI}$ is a relative value assigned to a diagnosis-related group of patients in a medical care environment and is used in determining the allocation of resources to care for and/or treat the patients in the group.

A sensitivity analysis was conducted on a second cohort that included a subset of patients from the preperiod between November 1, 2013, and April 30, 2014, and a subset of patients from the postperiod between November 1, 2014, and April 1, 2015, to control for the calendar period (supplementary Appendix 2).

All analyses were conducted in $\mathrm{R}$ version 3.3.0, with the linear mixed-effects model Ime4 statistical package. 13,14

\section{RESULTS}

Table 2 shows patient characteristics in the pre- and postperiods. There were no significant differences between age, sex, race and/or ethnicity, language, or $\mathrm{CMI}$ between patients in the pre- and postperiods. Discharge volume was higher by 1.3 patients per day in the postperiod compared with the preperiod $(P<.001)$.

Table 3 shows the differences in the outcomes between the pre- and postperiods. There was no change in the LOS or LOS adjusted for CMI. There was a 3.9\% increase in discharges before noon in the postperiod compared with the preperiod (95\% Cl, 2.4\% to 5.3\%; $P<.001$ ). There was a $9.9 \%$ increase in the percentage of patients for whom the EDD was recorded in our EHR within 24 hours of admission $(95 \% \mathrm{Cl}, 7.4 \%$ to $12.4 \%$; $P<.001)$. There was no change in the "top-box" patient satisfaction scores.

There were only marginal differences in the results between the entire cohort and a second subset cohort used for sensitivity analysis (supplementary Appendix 2).

\section{DISCUSSION}

In our study, there was no change in the mean LOS with the new model of MDR. There was an increase in discharges before noon and in recording of the EDD in our EHR within 24 hours of admission in the postperiod when the Lean-based new model of MDR was utilized. There was no change in patient satisfaction. With no change in staffing, we were able to accommodate the increase in the discharge volume in the postperiod.

We believe our results are attributable to several factors, including clearly defined roles and responsibilities for all participants of MDR, the inclusion of more experienced general medicine attending physician (compared with housestaff), Lean management techniques to identify gaps in the patient's journey from emergency department to discharge using VSM, the development of appropriate workflows and standard work on how the multidisciplinary teams would work together at RPIWs, and ADM to ensure sustainability and engagement among frontline members and institutional leaders. In order to sustain this, we planned to continue monitoring data in daily, weekly, and monthly forums with senior physician and administrative leaders. Planning for additional interventions is underway, including moving MDR to the bedside, instituting an afternoon "check-in" that would enable more detailed action planning, and addressing barriers in a timely manner for patients ready to discharge the following day.

Our study has a few limitations. First, this is an observational study that cannot determine causation. Second, this is a single-center study conducted on patients only on the general medicine teaching service. Third, there were several 
concurrent interventions implemented at our institution to improve LOS, throughput, and patient satisfaction in addition to MDR, thus making it difficult to isolate the impact of our intervention. Fourth, in the new model of MDR, rounds took place only 5 days per week, thereby possibly limiting the potential impact on our outcomes. Fifth, while we showed improvements in the discharges before noon and recording of EDD in the post period, we were not able to achieve our target of $25 \%$ discharges before noon or $100 \%$ recording of EDD in this time period. We believe the limited amount of time between the pre- and postperiods to allow for adoption and learning of the processes might have contributed to the underestimation of the impact of the new model of MDR, thereby limiting our ability to achieve our targets. Sixth, the response rate on the Press Ganey survey was low, and we did not directly survey patients or families for their satisfaction with MDR.

Our study has several strengths. To our knowledge, this is the first study to embed Lean management techniques in the design of MDR in the inpatient setting. While several studies have demonstrated improvements in discharges before noon through the implementation of MDR, they have not incorporated Lean management techniques, which we believe are critical to ensure the sustainability of results. ${ }^{1,3,5,6,8,15}$ Second, while it was not measured, there was a high level of provider engagement in the process in the new model of MDR. Third, because the MDR were conducted at the nurse's station on each inpatient unit in the new model instead of in a conference room, it was well attended by all members of the multidisciplinary team. Fourth, the presence of a visibility board allowed for all team members to have easy access to visual feedback throughout the day, even if they were not present at the MDR. Fifth, we believe that there was also more accurate estimation of the date and time of discharge in the new model of MDR because the discussion was facilitated by the case manager, who is experienced in identifying barriers to discharge (compared with the housestaff in the old model of MDR), and included the more experienced attending physician. Finally, the consistent presence of a multidisciplinary team at MDR allowed for the incorporation of everyone's concerns at one time, thereby limiting the need for paging multiple disciplines throughout the day, which led to quicker resolution of issues and assignment of pending tasks.

In conclusion, our study shows no change in the mean LOS when the Lean-based model of MDR was utilized. Our study demonstrates an increase in discharges before noon and in re- cording of EDD on our EHR within 24 hours of admission in the post period when the Lean-based model of MDR was utilized. There was no change in patient satisfaction. While this study was conducted at an academic medical center on the general medicine wards, we believe our new model of MDR, which leveraged Lean management techniques, may successfully impact patient flow in all inpatient clinical services and nonteaching hospitals.

Disclosure: The authors report no financial conflicts of interest and have nothing to disclose.

\section{References}

1. Townsend-Gervis M, Cornell P, Vardaman JM. Interdisciplinary Rounds and Structured Communication Reduce Re-Admissions and Improve Some Patient Outcomes. West J Nurs Res. 2014;36(7):917-928.

2. Vazirani S, Hays RD, Shapiro MF, Cowan M. Effect of a multidisciplinary intervention on communication and collaboration among physicians and nurses. Am J Crit Care. 2005;14(1):71-77.

3. Wertheimer B, Jacobs RE, Bailey M, et al. Discharge before noon: an achievable hospital goal. J Hosp Med. 2014;9(4):210-214.

4. Wertheimer B, Jacobs RE, Iturrate E, Bailey M, Hochman K. Discharge before noon: Effect on throughput and sustainability. J Hosp Med. 2015;10(10):664669.

5. Halm MA, Gagner S, Goering M, Sabo J, Smith M, Zaccagnini M. Interdisciplinary rounds: impact on patients, families, and staff. Clin Nurse Spec. 2003;17(3):133-142

6. O'Mahony S, Mazur E, Charney P, Wang Y, Fine J. Use of multidisciplinary rounds to simultaneously improve quality outcomes, enhance resident education, and shorten length of stay. J Gen Intern Med. 2007;22(8):1073-1079.

7. Reimer N, Herbener L. Round and round we go: rounding strategies to impact exemplary professional practice. Clin J Oncol Nurs. 2014;18(6):654-660

8. Curley C, McEachern JE, Speroff T. A firm trial of interdisciplinary rounds on the inpatient medical wards: an intervention designed using continuous quality improvement. Med Care. 1998;36(8 Suppl):AS4-AS12.

9. Baggs JG, Ryan SA, Phelps CE, Richeson JF, Johnson JE. The association between interdisciplinary collaboration and patient outcomes in a medical intensive care unit. Heart Lung. 1992;21(1):18-24.

10. Lawal AK, Rotter T, Kinsman L, et al. Lean management in health care: definition, concepts, methodology and effects reported (systematic review protocol). Syst Rev. 2014;3:103.

11. Liker JK. Toyota Way: 14 Management Principles from the World's Greatest Manufacturer. New York, Chicago, San Francisco, Athens, London, Madrid, Mexico City, Milan, New Delhi, Singapore, Sydney, Toronto: McGraw-Hill Education; 2004.

12. Kane M, Chui K, Rimicci J, et al. Lean Manufacturing Improves Emergency Department Throughput and Patient Satisfaction. J Nurs Adm. 2015;45(9):429-434

13. R Core Team. R: A language and environment for statistical computing. $R$ Foundation for Statistical Computing, Vienna, Austria. 2016. http://www.R-project.org/. Accessed November 7, 2017.

14. Bates D, Mächler M, Bolker B, Walker S. Fitting Linear Mixed-Effects Models Using Ime4. J Stat Softw. 2015;67(1):1-48.

15. O'Leary KJ, Buck R, Fligiel HM, et al. Structured interdisciplinary rounds in a medical teaching unit: improving patient safety. Arch Intern Med. 2011;171(7):678-684 